\title{
Use of TerraSAR-X Data to Retrieve Soil Moisture Over Bare Soil Agricultural Fields
}

\author{
Nicolas Baghdadi, Maelle Aubert, and Mehrez Zribi
}

\begin{abstract}
4 Abstract-The retrieval of the bare soil moisture content from 5 TerraSAR-X data is discussed using empirical approaches. Two 6 cases were evaluated: 1) one image at low or high incidence angle 7 and 2) two images, one at low incidence and one at high incidence. 8 This study shows by using three databases collected between 2008 9 and 2010 over two study sites in France (Orgeval and Villamblain) 10 that TerraSAR-X is a good remote sensing tool for the retrieving of 11 surface soil moisture with accuracy of about $3 \%$ (rmse). Moreover, 12 the accuracy of the soil moisture estimate does not improve when 13 two incidence angles $\left(26^{\circ}-\mathbf{2 8}^{\circ}\right.$ or $\left.\mathbf{5 0}^{\circ}-\mathbf{5 2}^{\circ}\right)$ are used instead of 14 only one. When compared with the result obtained with a high 15 incidence angle $\left(50^{\circ}-52^{\circ}\right)$, the use of low incidence angle $\left(26^{\circ}-28^{\circ}\right)$ 16 does not enable a significant improvement in estimating soil mois17 ture (about 1\%).
\end{abstract}

Index Terms-Soil moisture, TerraSAR-X images.

\section{INTRODUCTION}

${ }_{20}^{n} \mathbf{R}$ ADAR SIGNAL is a function of soil moisture and surface roughness in the case of bare soil. The possibility of 22 retrieving these soil parameters was little investigated from $23 \mathrm{X}$-band synthetic aperture radar (SAR). However, many studies 24 were carried out by using C-band radar data (e.g., [1]-[4]). With 25 the launch of satellites using the $\mathrm{X}$-band $(\sim 9.6 \mathrm{GHz})$, such as 26 TerraSAR-X and COSMO-SkyMed, the use of X-band data to 27 derive soil parameters became possible. A radar configuration 28 that minimizes the effects of surface roughness is recommended 29 for a better estimate of soil moisture when using only one 30 incidence angle. The optimal radar incidences in C-band for the 31 retrieval of soil moisture are smaller than $35^{\circ}$ [4].

32 Soil moisture estimation from SAR images is carried out by 33 using physical or statistical models. Physical approach consists 34 in using a physical model, such as the integral equation model 35 [5], to predict the radar backscattering coefficient from SAR 36 and soil parameters (wavelength, polarization, incidence angle, 37 surface roughness, and soil dielectric constant). Statistical mod38 els based on experimental measurements are also often used in 39 soil moisture estimation. For bare soils, the increase of radar 40 signal $\left(\sigma^{\circ}\right)$ is supposed to be linear with the volumetric soil

Manuscript received August 11, 2011; revised September 19, 2011; accepted October 17, 2011. This work was supported in part by the CEMAGREF (Agricultural and Environmental Engineering Research) and in part by the ORFEO Program, National Space Study Center (CNES).

N. Baghdadi and M. Aubert are with UMR TETIS, CEMAGREF, 34093 Montpellier, France (e-mail: nicolas.baghdadi@teledetection.fr; maelle. aubert@teledetection.fr).

M. Zribi is with Centre d'Etudes Spatiales de la BIOsphère, Institut de Recherche pour le Développement, 31401 Toulouse, France.

Color versions of one or more of the figures in this paper are available online at http://ieeexplore.ieee.org.

Digital Object Identifier 10.1109/LGRS.2011.2173155

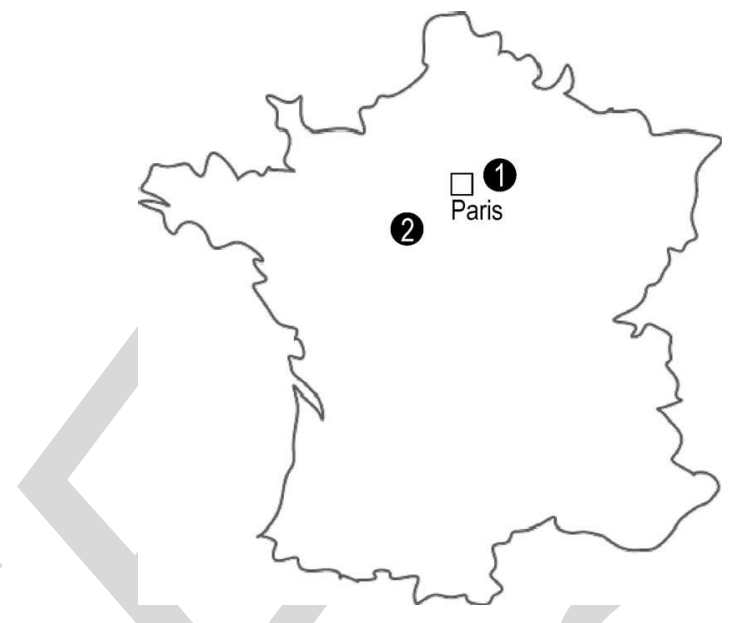

Fig. 1. Location of study sites. (1) Orgeval. (2) Villamblain.

moisture for values between $5 \%$ and $35 \%$ [6]. Moreover, $\sigma^{\circ}$ in- 41 creases with soil surface roughness and follows an exponential 42 or logarithmic behavior (e.g., [4] and [7]).

Very few studies analyzed the sensitivity of TerraSAR-X 44 data to bare soil surface parameters. Baghdadi et al. [8] have 45 observed that the radar signal at X-band is slightly more sen- 46 sitive to surface roughness at high incidence angle than at low 47 incidence angle. The difference observed between radar signals 48 reflected by the roughest and smoothest areas increases with the 49 radar wavelength. Moreover, results showed that the sensitivity 50 of radar signal to surface roughness is better with PALSAR in 51 L-band than with TerraSAR-X in X-band and that the C- and 52 $\mathrm{X}$-bands are similar sensitivity results. In this letter, only in 53 situ soil moisture measurements in very wet conditions between 54 $25 \%$ and $40 \%$ are available. Results obtained showed that the 55 backscattering coefficient at X-band is stable when the moisture 56 content ranges between $25 \%$ and $35 \%$ and that it decreases 57 beyond this threshold.

Aubert et al. [9] have showed that the sensitivity of the 59 TerraSAR-X signal to soil moisture is very important at low 60 and high incidence angles. In comparison to results published 61 with C-band SAR data, this sensitivity of the radar signal to 62 soil moisture is higher in X-band. The second important result 63 concerns the potential of the fine spatial resolution of TerraSAR 64 $(1 \mathrm{~m})$ in the detection of soil moisture variations at the within- 65 plot scale. The spatial distribution of slaking crust could be 66 detected when soil moisture variation is observed between soil 67 crusted and soil without crust. Indeed, areas covered by slaking 68 crust could have greater soil moisture and, consequently, a 69 greater backscattering signal than soils without crust. 
Author-produced version of the article published in IEEE Geoscience and remote sensing letters, 2012, 9(3), 512-516.

TABLE I

Characteristics of TerraSAR-X IMAges AND Summary of Ground-Truth MEASUREMEnTs ( $m v, r m s$, AND $L$ )

\begin{tabular}{|c|c|c|c|c|c|c|}
\hline $\begin{array}{c}\text { Date } \\
\text { dd-mm-yy }\end{array}$ & Site & Pol.-Inc. & $\begin{array}{c}\text { Fields } \\
\text { number }\end{array}$ & $\begin{array}{c}m v(\%) \\
\text { (min;max) }\end{array}$ & $\begin{array}{c}r m s(\mathrm{~cm}) \\
(\min ; \max )\end{array}$ & $\begin{array}{c}L(\mathrm{~cm}) \\
(\min ; \max )\end{array}$ \\
\hline $06-02-08$ & Villamblain & $H H-52^{\circ}$ & 8 & $(27 ; 34)$ & $(1.3 ; 3.1)$ & $(4.5 ; 9.1)$ \\
\hline $07-02-08$ & Villamblain & $H H-28^{\circ}$ & 8 & $(27 ; 34)$ & $(1.3 ; 3.1)$ & $(4.5 ; 9.1)$ \\
\hline $12-02-08$ & Orgeval & $H H-50^{\circ}$ & 6 & $(31 ; 36)$ & $(1.8 ; 3.3)$ & $(5.0 ; 9.3)$ \\
\hline $13-02-08$ & Orgeval & $H H-26^{\circ}$ & 6 & $(31 ; 35)$ & $(1.8 ; 3.3)$ & $(5.0 ; 9.3)$ \\
\hline $17-03-09$ & Orgeval & $H H-26^{\circ}$ & 7 & $(25 ; 32)$ & $(1.7 ; 2.3)$ & $(4.8 ; 6.9)$ \\
\hline $18-03-09$ & Orgeval & $H H-50^{\circ}$ & 7 & $(24 ; 30)$ & $(1.7 ; 2.3)$ & $(4.8 ; 6.9)$ \\
\hline $25-03-09$ & Orgeval & $H H-50^{\circ}$ & 3 & $(28 ; 29)$ & $(2.0 ; 2.7)$ & $(4.8 ; 5.7)$ \\
\hline $26-03-09$ & Orgeval & $H H-26^{\circ}$ & 3 & $(24 ; 31)$ & $(2.0 ; 2.7)$ & $(4.8 ; 5.7)$ \\
\hline 08-04-09 & Orgeval & $H H-26^{\circ}$ & 6 & $(17 ; 26)$ & $(1.1 ; 2.1)$ & $(3.7 ; 6.0)$ \\
\hline 09-04-09 & Orgeval & $H H-50^{\circ}$ & 6 & $(15 ; 26)$ & $(1.1 ; 2.1)$ & $(3.7 ; 6.0)$ \\
\hline $01-03-10$ & Orgeval & $H H-50^{\circ}$ & 6 & $(33 ; 40)$ & $(1.9 ; 2.9)$ & $(5.9 ; 7.5)$ \\
\hline $02-03-10$ & Orgeval & $H H-26^{\circ}$ & 6 & $(33 ; 37)$ & $(1.9 ; 2.9)$ & $(5.9 ; 7.5)$ \\
\hline $12-03-10$ & Orgeval & $H H-50^{\circ}$ & 7 & $(13 ; 25)$ & $(1.1 ; 2.6)$ & $(4.6 ; 7.0)$ \\
\hline $13-03-10$ & Orgeval & $H H-26^{\circ}$ & 7 & $(15 ; 22)$ & $(1.1 ; 2.6)$ & $(4.6 ; 7.0)$ \\
\hline
\end{tabular}

71 At least one research question remained open. It concerns 72 the precision of the soil moisture estimates in bare agricultural 73 soils. The objective of this study is to examine the potential of 74 TerraSAR-X data for retrieving volumetric soil moisture over 75 bare soils. This work evaluates if the use of two incidence 76 angles at X-band [one low $\left(26^{\circ}-28^{\circ}\right)$ and one high $\left(50^{\circ}-52^{\circ}\right)$ ] 77 improves the accuracy of the estimate of surface soil moisture 78 in comparison to only one incidence (low or high). TerraSAR-X 79 sensor has the advantage to acquire on the same study site 80 image pairs at low and high incidence angles within one day. 81 The goal of this work is to compare the findings with $\mathrm{C}$ - and $82 \mathrm{X}$-band data. At C-band, several studies have shown that the 83 use of two incidence angles provides distinct improvement in 84 the soil moisture estimate, in comparison with results obtained 85 using a single incidence (e.g., [1], [2], and [4]). Moreover, 86 low incidence angle is better than the high incidence angle 87 for estimating soil moisture with C-band SAR data. This letter 88 investigates this research question.

\section{Study AREA AND Data Set}

\section{A. Study Site}

91 Data were acquired over two mainly agricultural sites 92 (Fig. 1). The Villamblain site is located in the south of Paris, 93 France (latitude $48^{\circ} 01^{\prime} \mathrm{N}$ and longitude $1^{\circ} 35^{\prime} \mathrm{E}$ ) with soil 94 composed of $30 \%$ clay, $60 \%$ silt, and $10 \%$ sand. The second 95 site is situated in the Orgeval watershed, located in the east of 96 Paris, France (latitude $48^{\circ} 51^{\prime} \mathrm{N}$ and longitude $3^{\circ} 07^{\prime} \mathrm{E}$ ). The soil 97 has a loamy texture, composed of $78 \%$ silt, $17 \%$ clay, and $5 \%$ 98 sand. Both of these two sites are very flat.
During the period of February-April (our SAR acquisitions), 99 the main crops are wheat and colza. They cover approximately 100 $50 \%$ of the agricultural area. The remaining surface corre- 101 sponds to plowed soils awaiting future cultivation (corn and 102 potato).

\section{B. TerraSAR-X Images}

Fourteen TerraSAR-X images (X-band $\sim 9.65 \mathrm{GHz}$ ) were 105 acquired during the years of 2008, 2009, and 2010 (Table I). 106 The radar data are available in $\mathrm{HH}$ polarization, with incidence 107 angles $(\theta)$ of $26^{\circ}, 28^{\circ}, 50^{\circ}$, and $52^{\circ}$. The imaging mode 108 used was spotlight with a pixel spacing of $1 \mathrm{~m}$. Radiometric 109 calibration using multilook ground range detected TerraSAR-X 110 images was first carried out using the following equation [10]: 111

$$
\sigma_{i}^{\circ}(\mathrm{dB})=\log _{10}\left(K s \cdot D N_{i}^{2}-N E B N\right)+10 \log _{10}\left(\sin \theta_{i}\right) .
$$

This equation transforms the amplitude of backscattered sig- 112 nal for each pixel $\left(D N_{i}\right)$ into a backscattering coefficient $\left(\sigma^{\circ}\right) 113$ in decibels. $K s$ is the calibration coefficient, and $N E B N$ is 114 the noise equivalent beta naught. All TerraSAR-X images were 115 then georeferenced using GPS points with a root-mean-square 116 error of the control points of approximately one pixel (i.e., $1 \mathrm{~m}$ ). 117 This coregistration error was overcome by removing two 118 boundary pixels from each training plot relative to the limits 119 defined by the GPS control points. The mean backscattering 120 coefficients were calculated from calibrated SAR images by 121 averaging the linear $\sigma^{\circ}$ values of all pixels within reference 122 fields. 
Author-produced version of the article published in IEEE Geoscience and remote sensing letters, 2012, 9(3), 512-516.

The original publication is available at http://ieeexplore.ieee.org

http://dx.doi.org/10.1109/LGRS.2011.2173155

BAGHDADI et al: : USE OF TerraSAR-X DATA TO RETRIEVE SOIL MOISTURE OVER BARE SOIL AGRICULTURAL FIELDS

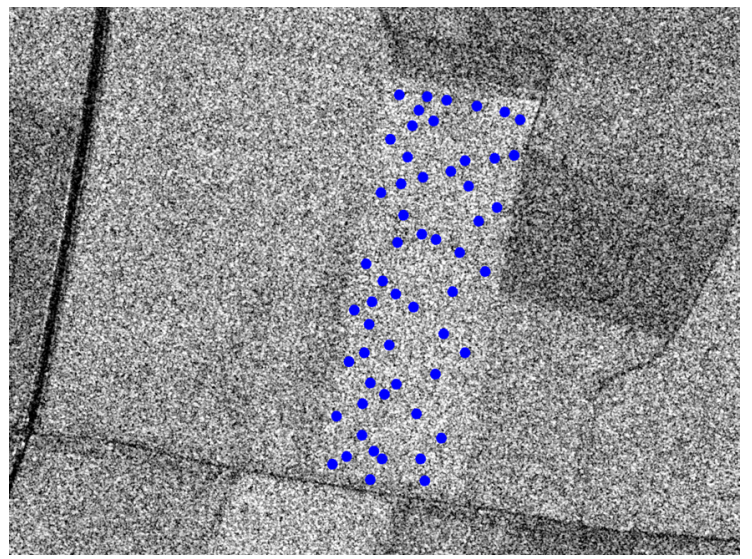

Fig. 2. Example of volumetric soil moisture measurements taken on a reference field.

\section{C. Field Data}

125 Simultaneously with TerraSAR-X acquisition, field mea126 surements of soil moisture and surface roughness have been 127 achieved on several bare soil reference fields of at least 2 ha. 128 In the case of TerraSAR-X in spotlight mode (pixel spacing of $1291 \mathrm{~m}$ ), this corresponds to a surface of 20000 pixels or more.

130 The volumetric water content at field scale was assumed to be 131 equal to the mean value estimated from several samples (20-40 132 measurements per field; Fig. 2) collected from the top $5 \mathrm{~cm}$ 133 of soil using the gravimetric method. The soil moistures range 134 from $13 \%$ to $40 \%$.

135 In most studies of microwave measurements carried out over 136 bare soils, the experimental relationship between soil moisture 137 and backscattering coefficient is provided by mean volumetric 138 water contents measured to a soil depth, generally $0-5 \mathrm{~cm}$ 139 or $0-10 \mathrm{~cm}$. Indeed, only some studies using theory results 140 are available at X-band. These studies suggest a penetration 141 depth maybe lower than $5 \mathrm{~cm}$. No experimental measurements 142 are made in field condition, and the low penetration depth 143 of X-band is only based on theoretical study. Therefore, the 144 penetration depth of the X-band is not yet well known.

145 Roughness measurements were made using needle pro146 filometers ( $1 \mathrm{~m}$ long and with 2 -cm sampling intervals). Ten 147 roughness profiles were sampled for each training field (parallel 148 and perpendicular to the row direction). From these measure149 ments, the two roughness parameters, i.e., root mean square 150 (rms) surface height and correlation length $(L)$, were calcu151 lated using the mean of all correlation functions. The rms 152 surface heights range from 1.1 to $3.3 \mathrm{~cm}$, and the correlation 153 length $(L)$ varies from $2.3 \mathrm{~cm}$ in sown fields to $9.3 \mathrm{~cm}$ in plowed 154 fields.

\section{Methodology}

156 The retrieval of soil moisture from TerraSAR-X images 157 by means of empirical approaches requires the development 158 of experimental relationships between $\sigma_{\text {TerraSAR-X }}^{\circ}$ and the 159 measured soil moisture. TerraSAR data acquired in two config160 urations of incidence angles $\left(\sim 26^{\circ}\right.$ and $\left.\sim 50^{\circ}\right)$ were used with 161 ground measurements conducted over bare soil. The sensitivity 162 of TerraSAR signal to soil moisture is the greatest for low

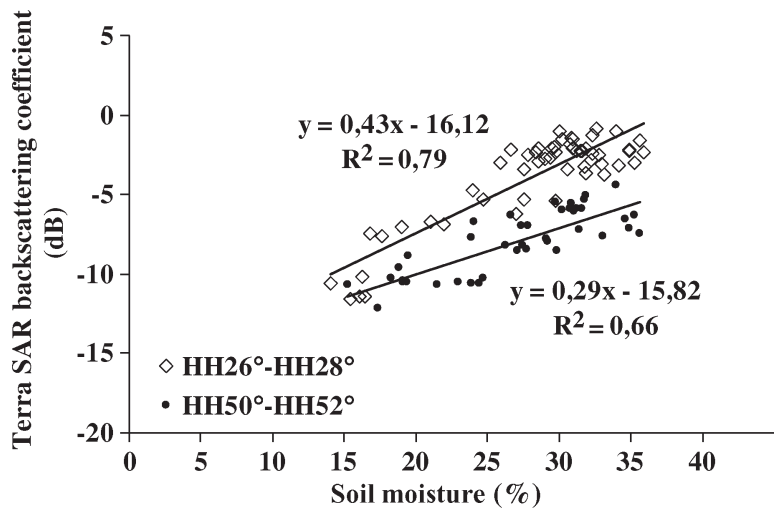

Fig. 3. TerraSAR-X signal versus volumetric soil moisture (measured at a depth of $5 \mathrm{~cm}$ ). Each point corresponds to the average backscattering coefficient in decibels for one reference field. Thirty points are used for each of the two configurations $\mathrm{HH} 26^{\circ}-28^{\circ}$ and $\mathrm{HH} 50^{\circ}-52^{\circ}$ (data sets of 2008 and 2009).

incidence angle $\left(0.43 \mathrm{~dB} / \%\right.$ for $26^{\circ}-28^{\circ}$ and $0.29 \mathrm{~dB} / \%$ for 163 $50^{\circ}-52^{\circ}$; Fig. 3). For a confidence level of $95 \%$, there are sig- 164 nificant relationships between the TerraSAR-X backscattering 165 coefficient and the in situ soil moisture because the $p$-values are 166 much less than 0.05 ( $p$-value $<2.2 \times 10^{-16}$ for $\mathrm{HH}_{2} 6^{\circ}-28^{\circ} 167 \mathrm{AQ8}$ and $p$-value $=1.52 \times 10^{-10}$ for $\mathrm{HH} 50^{\circ}-52^{\circ}$ ).

168

Studies using C-band (ERS, RADARSAT, ASAR, etc.) 169 AQ9 showed lower sensitivities between radar signal and soil mois- 170 ture, between 0.2 and $0.3 \mathrm{~dB} / \%$ for low incidence angles 171 and about $0.1 \mathrm{~dB} / \%$ for high incidence angles (e.g., [2] and 172 [11]-[13]).

The objective of this study is to analyze the influence of 174 incidence angle on the accuracy of the soil moisture estimate. 175 Configurations in $\mathrm{HH}$ polarization with single incidence an- 176 gle $\left(26^{\circ}-28^{\circ}\right.$ or $\left.50^{\circ}-52^{\circ}\right)$ were studied. Next, multi-incidence 177 TerraSAR-X images acquired at both low and high $\theta$ values 178 with one-day-spaced dates and only minor variations in soil 179 characteristics were used to analyze the possible improvement 180 in the soil moisture estimates when two incidences are used. 181

The empirical relationship between the radar backscattering 182 coefficient $\left(\sigma^{\circ}\right)$ and the volumetric soil moisture $(m v)$ for bare 183 soil surfaces without taking into account the $r m s$ surface height 184 is given by (e.g., [14]; Fig. 3)

$$
\sigma_{\mathrm{dB}}^{\circ}=f(m v, \theta)_{\mathrm{dB}}=\delta m v+\xi .
$$

This simplified relationship is valid for $m v$ values between 186 $5 \%$ and $35 \%$ [6]. The coefficient $\delta$ is dependent on SAR pa- 187 rameters (radar wavelength, incidence angle, and polarization), 188 while the coefficient $\xi$ is controlled by SAR parameters and 189 surface roughness. Experimental data of $\sigma^{\circ}$ and $m v$ show slope 190 $\delta$ values of about $0.43 \mathrm{~dB} / \%$ for $\mathrm{HH} 26^{\circ}-28^{\circ}$ and $0.29 \mathrm{~dB} / \%$ for 191 $\mathrm{HH} 50^{\circ}-52^{\circ}$.

The relationship obtained between $\sigma^{\circ}$ and the rms height 193 independent of row direction, correlation length, and soil mois- 194 ture could be written as an exponential relationship of the form 195 $\sigma_{\mathrm{dB}}^{\circ}=g(r m s, \theta)_{\mathrm{dB}}=\mu e^{-k r m s}+c$ [15], [16] or a logarithmic 196 relationship of the form $\sigma_{\mathrm{dB}}^{\circ}=g(r m s, \theta)_{\mathrm{dB}}=\mu \ln (r m s)+197$ $c[1]$.

With taking into account of both soil roughness and soil 199 moisture, the radar signal in decibel scale may be written as 200 
Author-produced version of the article published in IEEE Geoscience and remote sensing letters, 2012, 9(3), 512-516.

TABLE II

InVERsion Models for Estimating Soil Moisture and Statistics on the Validation of These Models

\begin{tabular}{|l|c|c|c|c|c|}
\hline \multicolumn{1}{|c|}{$\begin{array}{c}\text { TerraSAR- } \\
\mathrm{X} \text { data }-\mathrm{HH}\end{array}$} & \multicolumn{1}{|c|}{$\begin{array}{c}\text { Calibration phase } \\
\text { Model }\end{array}$} & $\mathrm{R}^{2}$ & \multicolumn{3}{|c|}{ Validation phase } \\
\hline $26^{\circ}-28^{\circ}$ & $m v(\%)=2.31 \sigma_{\mathrm{dB}}^{\circ}+37.19$ & 0.79 & 0.52 & 2.76 & 2.81 \\
$50^{\circ}-52^{\circ}$ & $m v(\%)=3.43 \sigma_{\mathrm{dB}}^{\circ}+54.30$ & 0.66 & 2.95 & 2.83 & 4.09 \\
\hline $26^{\circ}-28^{\circ}$ & $m v(\%)=1.67 \sigma_{\mathrm{dB}}^{\circ}\left(\theta_{\text {low }}\right)+0.55 \sigma_{\mathrm{dB}}^{\circ}\left(\theta_{\text {high }}\right)+38.22$ & 0.69 & 1.65 & 2.46 & 2.91 \\
and & & & & & \\
$50^{\circ}-52^{\circ}$ & & & & & \\
\hline
\end{tabular}

201 the sum of two functions that describe the dependence of the 202 radar signal on soil moisture $(f$ : linear) and surface roughness 203 ( $g$ : exponential) (e.g., [1] and [4])

$$
\sigma_{\mathrm{dB}}^{\circ}=f(m v, \theta)_{\mathrm{dB}}+g(r m s, \theta)_{\mathrm{dB}}=\delta, m v+\mu, e^{-k r m s}+\tau
$$

204 where $k$ is the radar wavenumber $\left(\sim 2 \mathrm{~cm}^{-1}\right.$ for TerraSAR-X). 205 This equation neglects the effect of the correlation length $206 L$ on the backscattering coefficient. To take account of the 207 correlation length, Zribi and Deschambre [1] proposed a new 208 roughness parameter $Z s$, defined by $\mathrm{rms}^{2} / L$, which is the 209 product of the rms surface height and the slope of the soil 210 surface $(r m s / L)$. Thus, the empirical model linking $\sigma^{\circ}$ and $Z s$ 211 could be written as $\sigma_{\mathrm{dB}}^{\circ}=\delta m v+\eta e^{-k Z s}+\psi$.

212 In the case of one SAR image characterized by one inci213 dence $\left(\theta=26^{\circ}-28^{\circ}\right.$ or $\left.50^{\circ}-52^{\circ}\right)$, inversion model is written as 214 follows:

$$
m v=\alpha \sigma^{\circ}(\theta)+\beta
$$

215 The use of two incidence angles eliminates the effects of 216 roughness and thus allows linking the backscattering coefficient 217 to the soil moisture only. For two images acquired with low 218 and high incidence angles, the estimate of soil moisture can 219 be obtained by solving (3) for two incidences (substituting the $220 e^{-k r m s}$ of $\sigma^{\circ}\left(\theta_{\text {low }}\right)$ into $\sigma^{\circ}\left(\theta_{\text {high }}\right)$

$$
m v=\alpha \sigma^{\circ}\left(\theta_{\text {low }}\right)+\beta \sigma^{\circ}\left(\theta_{\text {high }}\right)+\gamma .
$$

$221 \alpha$ and $\beta$ depend on $\delta$ and $\mu$, whereas $\gamma$ is a function of $\delta, \mu$, 222 and $\tau$ (in both incidence angles).

223 The form of (5) should be the same if the $Z s$ parameter was 224 used.

225 The empirical models given in (4) and (5) were then fitted to 226 experimental data acquired in 2008 and 2009 by using the least 227 squares method (cf. Table II). The validation of these models 228 was tested in using the data set of 2010 (13 points for each of 229 the two configurations $\mathrm{HH} 26^{\circ}$ and $\mathrm{HH} 50^{\circ}$ ). The inputs are the 230 mean backscattering coefficients in decibels calculated for each 231 reference field.

\section{RESUlTS AND DISCUSSION}

233 The inversion procedures were applied in order to retrieve 234 soil moisture. The results obtained in the validation phase 235 with one low incidence show inversion errors in the estimation

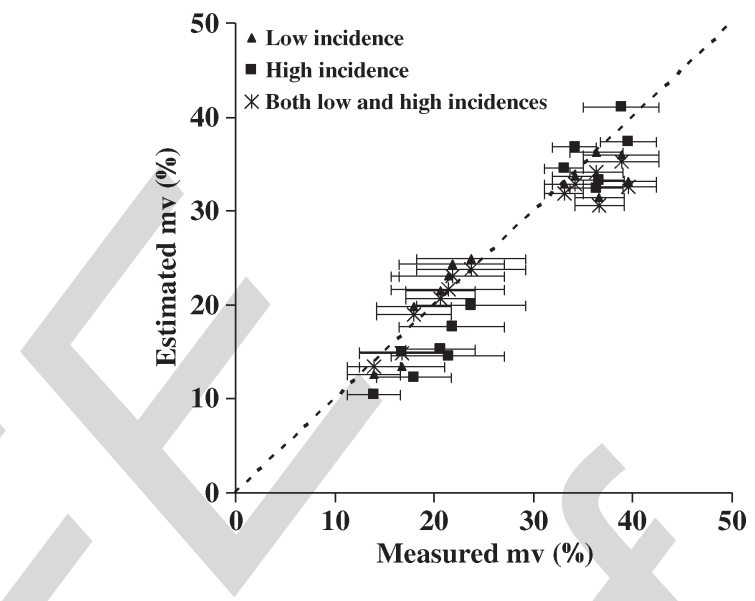

Fig. 4. Comparison between the estimated $m v$ values and those measured. The error bars on the measured soil moisture values correspond to one standard deviation.

of $m v$ of about 3\% for incidence angles. The use of high 236 incidences $\left(50^{\circ}-52^{\circ}\right)$ gives slightly poorer results with an rmse 237 of about $4 \%$. The accuracy of the soil moisture estimate remains 238 unchanged by using TerraSAR-X multi-incidence data (both 239 low and high incidence angles) with an rmse of about 3\% 240 (Table II). Fig. 4 shows the good agreement between estimated 241 and measured $m v$ values.

In contrast, large errors in the retrieved soil moisture were 243 observed at C-band for a single incidence angle (rmses of about 244 $6 \%$ for $20^{\circ}$ and $9 \%$ for $40^{\circ}$ ) [4]. This is due to the fact that the 245 radar signal is much more sensitive to surface roughness at high 246 radar wavelength. The accuracy is strongly improved with the 247 use of both low and high incidences (rmse of about 3.5\%) (e.g., 248 [1], [2], and [4]).

The dependence of the radar signal at X-band on surface 250 roughness in agricultural areas was described as weak by 251 several works ([8], [14], and [17]). Results of these studies 252 show that the influence of surface roughness on the radar signal 253 increases with increasing radar wavelength. Moreover, this 254 dependence is mainly significant for low levels of roughness. 255 At X-band, Baghdadi et al. [4], [8] showed that the sensitivity 256 of $\sigma^{\circ}$ to surface roughness becomes weak for $r m s>1 \mathrm{~cm} .257$ Thus, the effect of surface roughness on radar signal becomes 258 weak in X-band, which improves the estimates of soil moisture, 259 particularly for $r m s>1 \mathrm{~cm}$. Moreover, the multi-incidence 260 approaches become less effective because the effect of surface 261 roughness that we try to eliminate is relatively weak at X-band 262 compared to C-band. 
Author-produced version of the article published in IEEE Geoscience and remote sensing letters, 2012, 9(3), 512-516.

The original publication is available at http://ieeexplore.ieee.org

http://dx.doi.org/10.1109/LGRS.2011.2173155

BAGHDADI et al.: USE OF TerraSAR-X DATA TO RETRIEVE SOIL MOISTURE OVER BARE SOIL AGRICULTURAL FIELDS

TABLE III

TerraSAR-X Coverage Simulation For ORgeval Site Between SEPTEMBER 2 AND 12, 2010 (ORBIT CYCLE)

\begin{tabular}{|c|c|c|c|c|c|c|c|c|c|c|c|}
\hline \multirow{2}{*}{ Time } & $\begin{array}{c}02 \\
\text { sep. }\end{array}$ & $\begin{array}{c}03 \\
\text { sep. }\end{array}$ & $\begin{array}{c}04 \\
\text { sep. }\end{array}$ & $\begin{array}{c}05 \\
\text { sep. }\end{array}$ & $\begin{array}{c}06 \\
\text { sep. }\end{array}$ & $\begin{array}{c}07 \\
\text { sep. }\end{array}$ & $\begin{array}{c}08 \\
\text { sep. }\end{array}$ & $\begin{array}{c}09 \\
\text { sep. }\end{array}$ & $\begin{array}{c}10 \\
\text { sep. }\end{array}$ & $\begin{array}{c}11 \\
\text { sep. }\end{array}$ & $\begin{array}{c}12 \\
\text { sep. }\end{array}$ \\
\hline $\boldsymbol{\theta}\left(\mathbf{(}^{\circ}\right)$ & - & 39 & 58 & 50 & 26 & - & 26 & 50 & 58 & 39 & - \\
\hline
\end{tabular}

264

V. CONCLUSION

265 This study examined the potential of TerraSAR-X data for 266 estimating soil moisture $(m v)$ over bare soils. TerraSAR-X 267 images collected between 2008 and 2010 over two study sites in 268 France were used. SAR images were acquired at $\mathrm{HH}$ polariza269 tion and for incidence angles of $26^{\circ}, 28^{\circ}, 50^{\circ}$, and $52^{\circ}$. The goal 270 of this work was to compare estimates of $m v$ obtained from 271 various incidence configurations and to find the best sensor 272 configuration in incidence angle for measuring the bare soil 273 moisture.

274 This study tested empirical models for soil moisture inver275 sion from one incidence (low or high) and multi-incidence 276 TerraSAR-X data (both low and high incidences). The results 277 of this study may be summarized as follows. 286 plified algorithms for retrieving soil moisture from TerraSAR$287 \mathrm{X}$ data and for monitoring temporal moisture changes. Table III 288 lists the different observation possibilities for the Orgeval study 289 site within one orbit cycle (11 days). This site could be imaged 8 290 times within 11 days (two images for each following incidence: $291 \sim 26^{\circ}, 39^{\circ}, 50^{\circ}$, and $58^{\circ}$ ) and 24 times within one month. 292 The soil moisture mapping frequency with low incidence angle $293\left(26^{\circ}\right)$ or with both low and high incidence angles $\left(26^{\circ}\right.$ and $\left.50^{\circ}\right)$ 294 is possible six times within one month. The incidence of $39^{\circ} \mathrm{can}$ 295 also be used, which would increase to 12 the TerraSAR-X scene 296 number within one month. This very short revisit time makes 297 TerraSAR-X a very useful source for the soil moisture mapping. 298 Moreover, the increase in the acquisition frequency is much 299 awaited for the soil moisture data assimilation in hydrological 300 modeling.

301 In addition, the very high spatial resolution (metric) of the 302 TerraSAR-X sensor is also very promising for local estimation 303 of soil moisture at the within agricultural field scale. It offers a 304 great potential in terms of improving the quality of soil moisture 305 mapping for catchment areas where the parcels are of small 306 size.

\section{ACKNOWLEDGMENT}

308 The authors would like to thank the German Space Agency 309 (DLR) for kindly providing TerraSAR-X images within the framework of proposals HYD0007 and HYD0542, P. Ansart, 310 Y. Hachouch, and C. Loumagne for their logistic support during 311 the field campaigns, and TerraSAR-X Science Coordinators 312 A. Roth and U. Marschalk for their assistance.

\section{REFERENCES}

[1] M. Zribi and M. Dechambre, "A new empirical model to retrieve soil 315 moisture and roughness from C-band radar data," Remote Sens. Environ., 316 vol. 84, no. 1, pp. 42-52, Jan. 2003.

317

[2] H. S. Srivastava, P. Patel, M. L. Manchanda, and S. Adiga, "Use of 318 multi-incidence angle RADARSAT-1 SAR data to incorporate the effect 319 of surface roughness in soil moisture estimation," IEEE Trans. Geosci. 320 Remote Sens., vol. 41, no. 7, pp. 1638-1640, Jul. 2003.

321

[3] Y. Oh, "Quantitative retrieval of soil moisture content and surface rough- 322 ness from multipolarized radar observations of bare soil surfaces," IEEE 323 Trans. Geosci. Remote Sens., vol. 42, no. 3, pp. 596-601, Mar. $2004 . \quad 324$

[4] N. Baghdadi, N. Holah, and M. Zribi, "Soil moisture estimation using 325 multi-incidence and multi-polarization ASAR SAR data," Int. J. Remote 326 Sens., vol. 27, no. 10, pp. 1907-1920, 2006.

[5] A. K. Fung, Microwave Scattering and Emission Models and Their Appli- 328 cations. Boston, MA: Artech House, 1994, 573 pages.

[6] H. Holah, N. Baghdadi, M. Zribi, A. Bruand, and C. King, "Potential of 330 ASAR/ENVISAT for the characterisation of soil surface parameters over 331 bare agricultural fields," Remote Sens. Environ., vol. 96, no. 1, pp. 78-86, 332 May 2005.

333

7] F. T. Ulaby, P. P. Batlivala, and M. C. Dobson, "Microwave backscat- 334 ter dependence on surface roughness, soil moisture, and soil texture: 335 Part I-Bare soil," IEEE Trans. Geosci. Electron., vol. GE-16, no. 4, 336 pp. 286-295, Oct. 1978.

337

[8] N. Baghdadi, M. Zribi, C. Loumagne, P. Ansart, and T. Paris Anguela, 338 "Analysis of TerraSAR-X data and their sensitivity to soil surface parame- 339 ters over bare agricultural fields," Remote Sens. Environ., vol. 112, no. 12, 340 pp. 4370-4379, Dec. 2008.

341

[9] M. Aubert, N. Baghdadi, M. Zribi, A. Douaoui, C. Loumagne, F. Baup, 342 M. El Hajj, and S. Garrigues, "Analysis of TerraSAR-X data sensitivity to 343 bare soil moisture, roughness, composition and soil crust," Remote Sens. 344 Environ., vol. 115, no. 8, pp. 1801-1810, Aug. 2011.

[10] T. Fritz, TerraSAR-X Ground Segment Level 1b Product Format 346 Specification (10.12.2007), p. 257, 2007, Issue, 1.3, Doc.: TX-GS-DD- 347 3307. [Online]. Available: http://www.dlr.de/tsx/documentation/TX-GS- 348 DD-3307_Level-1b-Product-Format-Specification_1.3.pdf 349

[11] N. Baghdadi, O. Cerdan, M. Zribi, V. Auzet, F. Darboux, M. El Hajj, 350 and R. Bou Kheir, "Operational performance of current synthetic aper- 351 ture radar sensors in mapping soil surface characteristics: Application to 352 hydrological and erosion modeling," Hydrol. Process., vol. 22, no. 1, 353 pp. 9-20, Jan. 2008.

354

12] S. Le Hégarat-Mascle, M. Zribi, F. Alem, A. Weisse, and C. Loumagne, 355 "Soil moisture estimation from ERS/SAR data: Toward an operational 356 methodology," IEEE Trans. Geosci. Remote Sens., vol. GRS-24, no. 12, 357 pp. 2647-2658, Dec. 2002.

358

[13] A. Quesney, S. Le Hégarat-Mascle, O. Taconet, D. Vidal-Madjar, 359 J. P. Wingneron, C. Loumagne, and M. Normand, "Estimation of water- 360 shed soil moisture index from ERS/SAR data," Remote Sens. Environ., 361 vol. 72, no. 3, pp. 290-303, Jun. 2000.

362

[14] F. T. Ulaby, R. K. Moore, and A. K. Fung, Microwave Remote Sensing, 363 Active and Passive, From Theory to Applications, vol. 3. Norwood, MA: 364 Artech House, 1986, 1098 pages.

365

[15] Y. Oh, K. Sarabandi, and F. T. Ulaby, "An empirical model and an inver- 366 sion technique for radar scattering from bare soil surfaces," IEEE Trans. 367 Geosci. Remote Sens., vol. 30, no. 2, pp. 370-381, Mar. 1992.

368

[16] N. Baghdadi, C. King, A. Bourguignon, and A. Remond, "Potential of 369 ERS and RADARSAT data for surface roughness monitoring over bare 370 agricultural fields: Application to catchments in Northern France," Int. J. 371 Remote Sens., vol. 23, no. 17, pp. 3427-3442, 2002.

372

[17] N. Baghdadi, N. Holah, P. Dubois, L. Prévot, S. Hosford, A. Chanzy, 373 X. Dupuis, and M. Zribi, "Discrimination potential of X-band polari- 374 metric SAR data," Int. J. Remote Sens., vol. 25, no. 22, pp. 4933-4942, 375 2004. 


\section{AUTHOR QUERIES}

\section{AUTHOR PLEASE ANSWER ALL QUERIES}

AQ1 = "In" was changed to "by." Please check if the original thought was retained.

AQ2 = Please provide the expanded form of the acronym "COSMO-SkyMed."

AQ3 = Please provide the expanded form of the acronym "ORFEO."

AQ4 = "French Space Study Center" was changed to "National Space Study Center." Please check if appropriate.

AQ5 = Please provide the expanded form of the acronym "UMR TETIS."

AQ6 = The acronyms "CESBIO" and "IRD" were defined as "Centre d'Etudes Spatiales de la BIOsphère" and "Institut de Recherche pour le Développement," respectively. Please check if appropriate.

AQ7 = Please provide the expanded form of the acronym "PALSAR."

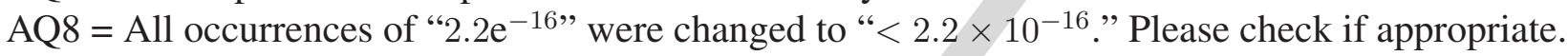
AQ9 = Please provide the expanded forms of the acronyms "ERS," "RADARSAT," and "ASAR."

AQ10 = This sentence was reworded for clarity. Please check if the original thought was retained.

AQ11 = Please check the URL provided in Ref. [10]. Page was not found.

END OF ALL QUERIES 


\title{
Use of TerraSAR-X Data to Retrieve Soil Moisture Over Bare Soil Agricultural Fields
}

\author{
Nicolas Baghdadi, Maelle Aubert, and Mehrez Zribi
}

\begin{abstract}
4 Abstract-The retrieval of the bare soil moisture content from 5 TerraSAR-X data is discussed using empirical approaches. Two 6 cases were evaluated: 1) one image at low or high incidence angle 7 and 2) two images, one at low incidence and one at high incidence. 8 This study shows by using three databases collected between 2008 9 and 2010 over two study sites in France (Orgeval and Villamblain) 10 that TerraSAR-X is a good remote sensing tool for the retrieving of 11 surface soil moisture with accuracy of about $3 \%$ (rmse). Moreover, 12 the accuracy of the soil moisture estimate does not improve when 13 two incidence angles $\left(26^{\circ}-\mathbf{2 8}^{\circ}\right.$ or $\left.\mathbf{5 0}^{\circ}-\mathbf{5 2}^{\circ}\right)$ are used instead of 14 only one. When compared with the result obtained with a high 15 incidence angle $\left(50^{\circ}-52^{\circ}\right)$, the use of low incidence angle $\left(26^{\circ}-28^{\circ}\right)$ 16 does not enable a significant improvement in estimating soil mois17 ture (about 1\%).
\end{abstract}

Index Terms-Soil moisture, TerraSAR-X images.

\section{INTRODUCTION}

${ }_{20}^{n} \mathbf{R}$ ADAR SIGNAL is a function of soil moisture and surface roughness in the case of bare soil. The possibility of 22 retrieving these soil parameters was little investigated from $23 \mathrm{X}$-band synthetic aperture radar (SAR). However, many studies 24 were carried out by using C-band radar data (e.g., [1]-[4]). With 25 the launch of satellites using the $\mathrm{X}$-band $(\sim 9.6 \mathrm{GHz})$, such as 26 TerraSAR-X and COSMO-SkyMed, the use of X-band data to 27 derive soil parameters became possible. A radar configuration 28 that minimizes the effects of surface roughness is recommended 29 for a better estimate of soil moisture when using only one 30 incidence angle. The optimal radar incidences in C-band for the 31 retrieval of soil moisture are smaller than $35^{\circ}$ [4].

32 Soil moisture estimation from SAR images is carried out by 33 using physical or statistical models. Physical approach consists 34 in using a physical model, such as the integral equation model 35 [5], to predict the radar backscattering coefficient from SAR 36 and soil parameters (wavelength, polarization, incidence angle, 37 surface roughness, and soil dielectric constant). Statistical mod38 els based on experimental measurements are also often used in 39 soil moisture estimation. For bare soils, the increase of radar 40 signal $\left(\sigma^{\circ}\right)$ is supposed to be linear with the volumetric soil

Manuscript received August 11, 2011; revised September 19, 2011; accepted October 17, 2011. This work was supported in part by the CEMAGREF (Agricultural and Environmental Engineering Research) and in part by the ORFEO Program, National Space Study Center (CNES).

N. Baghdadi and M. Aubert are with UMR TETIS, CEMAGREF, 34093 Montpellier, France (e-mail: nicolas.baghdadi@teledetection.fr; maelle. aubert@teledetection.fr).

M. Zribi is with Centre d'Etudes Spatiales de la BIOsphère, Institut de Recherche pour le Développement, 31401 Toulouse, France.

Color versions of one or more of the figures in this paper are available online at http://ieeexplore.ieee.org.

Digital Object Identifier 10.1109/LGRS.2011.2173155

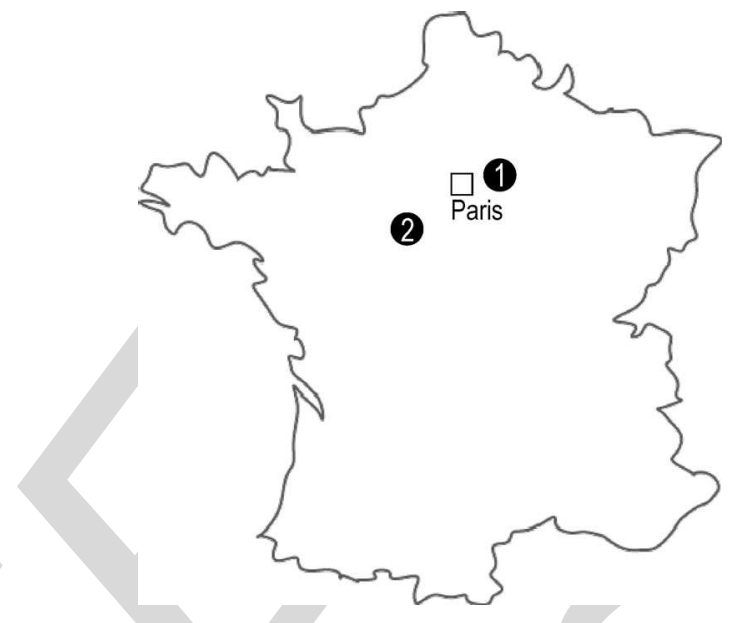

Fig. 1. Location of study sites. (1) Orgeval. (2) Villamblain.

moisture for values between $5 \%$ and $35 \%$ [6]. Moreover, $\sigma^{\circ}$ in- 41 creases with soil surface roughness and follows an exponential 42 or logarithmic behavior (e.g., [4] and [7]).

Very few studies analyzed the sensitivity of TerraSAR-X 44 data to bare soil surface parameters. Baghdadi et al. [8] have 45 observed that the radar signal at X-band is slightly more sen- 46 sitive to surface roughness at high incidence angle than at low 47 incidence angle. The difference observed between radar signals 48 reflected by the roughest and smoothest areas increases with the 49 radar wavelength. Moreover, results showed that the sensitivity 50 of radar signal to surface roughness is better with PALSAR in 51 L-band than with TerraSAR-X in X-band and that the C- and 52 $\mathrm{X}$-bands are similar sensitivity results. In this letter, only in 53 situ soil moisture measurements in very wet conditions between 54 $25 \%$ and $40 \%$ are available. Results obtained showed that the 55 backscattering coefficient at X-band is stable when the moisture 56 content ranges between $25 \%$ and $35 \%$ and that it decreases 57 beyond this threshold.

Aubert et al. [9] have showed that the sensitivity of the 59 TerraSAR-X signal to soil moisture is very important at low 60 and high incidence angles. In comparison to results published 61 with C-band SAR data, this sensitivity of the radar signal to 62 soil moisture is higher in X-band. The second important result 63 concerns the potential of the fine spatial resolution of TerraSAR 64 $(1 \mathrm{~m})$ in the detection of soil moisture variations at the within- 65 plot scale. The spatial distribution of slaking crust could be 66 detected when soil moisture variation is observed between soil 67 crusted and soil without crust. Indeed, areas covered by slaking 68 crust could have greater soil moisture and, consequently, a 69 greater backscattering signal than soils without crust. 
Author-produced version of the article published in IEEE Geoscience and remote sensing letters, 2012, 9(3), 512-516.

TABLE I

Characteristics of TerraSAR-X IMAges AND Summary of Ground-Truth MEASUREMEnTs ( $m v, r m s$, AND $L$ )

\begin{tabular}{|c|c|c|c|c|c|c|}
\hline $\begin{array}{c}\text { Date } \\
\text { dd-mm-yy }\end{array}$ & Site & Pol.-Inc. & $\begin{array}{c}\text { Fields } \\
\text { number }\end{array}$ & $\begin{array}{c}m v(\%) \\
\text { (min;max) }\end{array}$ & $\begin{array}{c}r m s(\mathrm{~cm}) \\
(\min ; \max )\end{array}$ & $\begin{array}{c}L(\mathrm{~cm}) \\
(\min ; \max )\end{array}$ \\
\hline $06-02-08$ & Villamblain & $H H-52^{\circ}$ & 8 & $(27 ; 34)$ & $(1.3 ; 3.1)$ & $(4.5 ; 9.1)$ \\
\hline $07-02-08$ & Villamblain & $H H-28^{\circ}$ & 8 & $(27 ; 34)$ & $(1.3 ; 3.1)$ & $(4.5 ; 9.1)$ \\
\hline $12-02-08$ & Orgeval & $H H-50^{\circ}$ & 6 & $(31 ; 36)$ & $(1.8 ; 3.3)$ & $(5.0 ; 9.3)$ \\
\hline $13-02-08$ & Orgeval & $H H-26^{\circ}$ & 6 & $(31 ; 35)$ & $(1.8 ; 3.3)$ & $(5.0 ; 9.3)$ \\
\hline $17-03-09$ & Orgeval & $H H-26^{\circ}$ & 7 & $(25 ; 32)$ & $(1.7 ; 2.3)$ & $(4.8 ; 6.9)$ \\
\hline $18-03-09$ & Orgeval & $H H-50^{\circ}$ & 7 & $(24 ; 30)$ & $(1.7 ; 2.3)$ & $(4.8 ; 6.9)$ \\
\hline $25-03-09$ & Orgeval & $H H-50^{\circ}$ & 3 & $(28 ; 29)$ & $(2.0 ; 2.7)$ & $(4.8 ; 5.7)$ \\
\hline $26-03-09$ & Orgeval & $H H-26^{\circ}$ & 3 & $(24 ; 31)$ & $(2.0 ; 2.7)$ & $(4.8 ; 5.7)$ \\
\hline 08-04-09 & Orgeval & $H H-26^{\circ}$ & 6 & $(17 ; 26)$ & $(1.1 ; 2.1)$ & $(3.7 ; 6.0)$ \\
\hline 09-04-09 & Orgeval & $H H-50^{\circ}$ & 6 & $(15 ; 26)$ & $(1.1 ; 2.1)$ & $(3.7 ; 6.0)$ \\
\hline $01-03-10$ & Orgeval & $H H-50^{\circ}$ & 6 & $(33 ; 40)$ & $(1.9 ; 2.9)$ & $(5.9 ; 7.5)$ \\
\hline $02-03-10$ & Orgeval & $H H-26^{\circ}$ & 6 & $(33 ; 37)$ & $(1.9 ; 2.9)$ & $(5.9 ; 7.5)$ \\
\hline $12-03-10$ & Orgeval & $H H-50^{\circ}$ & 7 & $(13 ; 25)$ & $(1.1 ; 2.6)$ & $(4.6 ; 7.0)$ \\
\hline $13-03-10$ & Orgeval & $H H-26^{\circ}$ & 7 & $(15 ; 22)$ & $(1.1 ; 2.6)$ & $(4.6 ; 7.0)$ \\
\hline
\end{tabular}

71 At least one research question remained open. It concerns 72 the precision of the soil moisture estimates in bare agricultural 73 soils. The objective of this study is to examine the potential of 74 TerraSAR-X data for retrieving volumetric soil moisture over 75 bare soils. This work evaluates if the use of two incidence 76 angles at X-band [one low $\left(26^{\circ}-28^{\circ}\right)$ and one high $\left(50^{\circ}-52^{\circ}\right)$ ] 77 improves the accuracy of the estimate of surface soil moisture 78 in comparison to only one incidence (low or high). TerraSAR-X 79 sensor has the advantage to acquire on the same study site 80 image pairs at low and high incidence angles within one day. 81 The goal of this work is to compare the findings with $\mathrm{C}$ - and $82 \mathrm{X}$-band data. At C-band, several studies have shown that the 83 use of two incidence angles provides distinct improvement in 84 the soil moisture estimate, in comparison with results obtained 85 using a single incidence (e.g., [1], [2], and [4]). Moreover, 86 low incidence angle is better than the high incidence angle 87 for estimating soil moisture with C-band SAR data. This letter 88 investigates this research question.

\section{Study AREA AND Data Set}

\section{A. Study Site}

91 Data were acquired over two mainly agricultural sites 92 (Fig. 1). The Villamblain site is located in the south of Paris, 93 France (latitude $48^{\circ} 01^{\prime} \mathrm{N}$ and longitude $1^{\circ} 35^{\prime} \mathrm{E}$ ) with soil 94 composed of $30 \%$ clay, $60 \%$ silt, and $10 \%$ sand. The second 95 site is situated in the Orgeval watershed, located in the east of 96 Paris, France (latitude $48^{\circ} 51^{\prime} \mathrm{N}$ and longitude $3^{\circ} 07^{\prime} \mathrm{E}$ ). The soil 97 has a loamy texture, composed of $78 \%$ silt, $17 \%$ clay, and $5 \%$ 98 sand. Both of these two sites are very flat.
During the period of February-April (our SAR acquisitions), 99 the main crops are wheat and colza. They cover approximately 100 $50 \%$ of the agricultural area. The remaining surface corre- 101 sponds to plowed soils awaiting future cultivation (corn and 102 potato).

\section{B. TerraSAR-X Images}

Fourteen TerraSAR-X images (X-band $\sim 9.65 \mathrm{GHz}$ ) were 105 acquired during the years of 2008, 2009, and 2010 (Table I). 106 The radar data are available in $\mathrm{HH}$ polarization, with incidence 107 angles $(\theta)$ of $26^{\circ}, 28^{\circ}, 50^{\circ}$, and $52^{\circ}$. The imaging mode 108 used was spotlight with a pixel spacing of $1 \mathrm{~m}$. Radiometric 109 calibration using multilook ground range detected TerraSAR-X 110 images was first carried out using the following equation [10]: 111

$$
\sigma_{i}^{\circ}(\mathrm{dB})=\log _{10}\left(K s \cdot D N_{i}^{2}-N E B N\right)+10 \log _{10}\left(\sin \theta_{i}\right) .
$$

This equation transforms the amplitude of backscattered sig- 112 nal for each pixel $\left(D N_{i}\right)$ into a backscattering coefficient $\left(\sigma^{\circ}\right) 113$ in decibels. $K s$ is the calibration coefficient, and $N E B N$ is 114 the noise equivalent beta naught. All TerraSAR-X images were 115 then georeferenced using GPS points with a root-mean-square 116 error of the control points of approximately one pixel (i.e., $1 \mathrm{~m}$ ). 117 This coregistration error was overcome by removing two 118 boundary pixels from each training plot relative to the limits 119 defined by the GPS control points. The mean backscattering 120 coefficients were calculated from calibrated SAR images by 121 averaging the linear $\sigma^{\circ}$ values of all pixels within reference 122 fields. 
Author-produced version of the article published in IEEE Geoscience and remote sensing letters, 2012, 9(3), 512-516.

The original publication is available at http://ieeexplore.ieee.org

http://dx.doi.org/10.1109/LGRS.2011.2173155

BAGHDADI et al: : USE OF TerraSAR-X DATA TO RETRIEVE SOIL MOISTURE OVER BARE SOIL AGRICULTURAL FIELDS

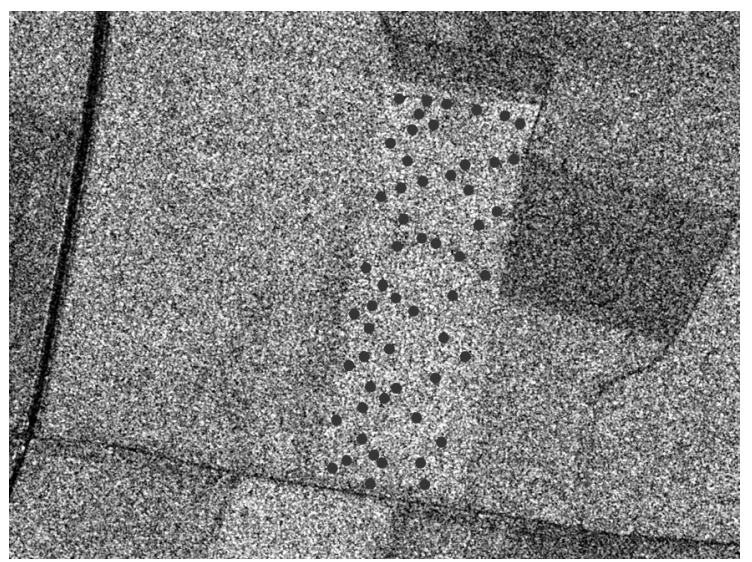

Fig. 2. Example of volumetric soil moisture measurements taken on a reference field.

\section{C. Field Data}

125 Simultaneously with TerraSAR-X acquisition, field mea126 surements of soil moisture and surface roughness have been 127 achieved on several bare soil reference fields of at least 2 ha. 128 In the case of TerraSAR-X in spotlight mode (pixel spacing of $1291 \mathrm{~m}$ ), this corresponds to a surface of 20000 pixels or more.

130 The volumetric water content at field scale was assumed to be 131 equal to the mean value estimated from several samples (20-40 132 measurements per field; Fig. 2) collected from the top $5 \mathrm{~cm}$ 133 of soil using the gravimetric method. The soil moistures range 134 from $13 \%$ to $40 \%$.

135 In most studies of microwave measurements carried out over 136 bare soils, the experimental relationship between soil moisture 137 and backscattering coefficient is provided by mean volumetric 138 water contents measured to a soil depth, generally $0-5 \mathrm{~cm}$ 139 or $0-10 \mathrm{~cm}$. Indeed, only some studies using theory results 140 are available at X-band. These studies suggest a penetration 141 depth maybe lower than $5 \mathrm{~cm}$. No experimental measurements 142 are made in field condition, and the low penetration depth 143 of X-band is only based on theoretical study. Therefore, the 144 penetration depth of the X-band is not yet well known.

145 Roughness measurements were made using needle pro146 filometers ( $1 \mathrm{~m}$ long and with 2 -cm sampling intervals). Ten 147 roughness profiles were sampled for each training field (parallel 148 and perpendicular to the row direction). From these measure149 ments, the two roughness parameters, i.e., root mean square 150 (rms) surface height and correlation length $(L)$, were calcu151 lated using the mean of all correlation functions. The rms 152 surface heights range from 1.1 to $3.3 \mathrm{~cm}$, and the correlation 153 length $(L)$ varies from $2.3 \mathrm{~cm}$ in sown fields to $9.3 \mathrm{~cm}$ in plowed 154 fields.

\section{Methodology}

156 The retrieval of soil moisture from TerraSAR-X images 157 by means of empirical approaches requires the development 158 of experimental relationships between $\sigma_{\text {TerraSAR-X }}^{\circ}$ and the 159 measured soil moisture. TerraSAR data acquired in two config160 urations of incidence angles $\left(\sim 26^{\circ}\right.$ and $\left.\sim 50^{\circ}\right)$ were used with 161 ground measurements conducted over bare soil. The sensitivity 162 of TerraSAR signal to soil moisture is the greatest for low

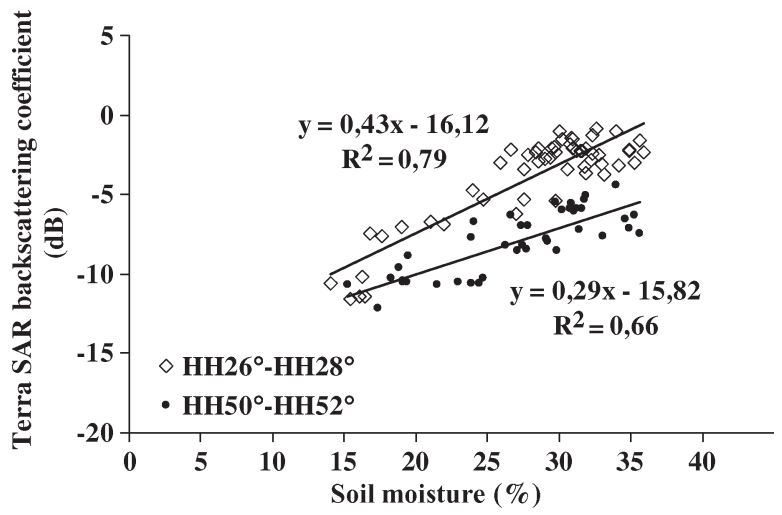

Fig. 3. TerraSAR-X signal versus volumetric soil moisture (measured at a depth of $5 \mathrm{~cm}$ ). Each point corresponds to the average backscattering coefficient in decibels for one reference field. Thirty points are used for each of the two configurations $\mathrm{HH} 26^{\circ}-28^{\circ}$ and $\mathrm{HH} 50^{\circ}-52^{\circ}$ (data sets of 2008 and 2009).

incidence angle $\left(0.43 \mathrm{~dB} / \%\right.$ for $26^{\circ}-28^{\circ}$ and $0.29 \mathrm{~dB} / \%$ for 163 $50^{\circ}-52^{\circ}$; Fig. 3). For a confidence level of $95 \%$, there are sig- 164 nificant relationships between the TerraSAR-X backscattering 165 coefficient and the in situ soil moisture because the $p$-values are 166 much less than 0.05 ( $p$-value $<2.2 \times 10^{-16}$ for $\mathrm{HH} 26^{\circ}-28^{\circ} 167 \mathrm{AQ8}$ and $p$-value $=1.52 \times 10^{-10}$ for $\mathrm{HH} 50^{\circ}-52^{\circ}$ ).

168

Studies using C-band (ERS, RADARSAT, ASAR, etc.) 169 AQ9 showed lower sensitivities between radar signal and soil mois- 170 ture, between 0.2 and $0.3 \mathrm{~dB} / \%$ for low incidence angles 171 and about $0.1 \mathrm{~dB} / \%$ for high incidence angles (e.g., [2] and 172 [11]-[13]).

The objective of this study is to analyze the influence of 174 incidence angle on the accuracy of the soil moisture estimate. 175 Configurations in $\mathrm{HH}$ polarization with single incidence an- 176 gle $\left(26^{\circ}-28^{\circ}\right.$ or $\left.50^{\circ}-52^{\circ}\right)$ were studied. Next, multi-incidence 177 TerraSAR-X images acquired at both low and high $\theta$ values 178 with one-day-spaced dates and only minor variations in soil 179 characteristics were used to analyze the possible improvement 180 in the soil moisture estimates when two incidences are used. 181

The empirical relationship between the radar backscattering 182 coefficient $\left(\sigma^{\circ}\right)$ and the volumetric soil moisture $(m v)$ for bare 183 soil surfaces without taking into account the $r m s$ surface height 184 is given by (e.g., [14]; Fig. 3)

$$
\sigma_{\mathrm{dB}}^{\circ}=f(m v, \theta)_{\mathrm{dB}}=\delta m v+\xi .
$$

This simplified relationship is valid for $m v$ values between 186 $5 \%$ and $35 \%$ [6]. The coefficient $\delta$ is dependent on SAR pa- 187 rameters (radar wavelength, incidence angle, and polarization), 188 while the coefficient $\xi$ is controlled by SAR parameters and 189 surface roughness. Experimental data of $\sigma^{\circ}$ and $m v$ show slope 190 $\delta$ values of about $0.43 \mathrm{~dB} / \%$ for $\mathrm{HH} 26^{\circ}-28^{\circ}$ and $0.29 \mathrm{~dB} / \%$ for 191 $\mathrm{HH} 50^{\circ}-52^{\circ}$.

The relationship obtained between $\sigma^{\circ}$ and the rms height 193 independent of row direction, correlation length, and soil mois- 194 ture could be written as an exponential relationship of the form 195 $\sigma_{\mathrm{dB}}^{\circ}=g(r m s, \theta)_{\mathrm{dB}}=\mu e^{-k r m s}+c$ [15], [16] or a logarithmic 196 relationship of the form $\sigma_{\mathrm{dB}}^{\circ}=g(r m s, \theta)_{\mathrm{dB}}=\mu \ln (r m s)+197$ $c[1]$.

With taking into account of both soil roughness and soil 199 moisture, the radar signal in decibel scale may be written as 200 
Author-produced version of the article published in IEEE Geoscience and remote sensing letters, 2012, 9(3), 512-516.

TABLE II

InVERsion Models for Estimating Soil Moisture and Statistics on the Validation of These Models

\begin{tabular}{|l|c|c|c|c|c|}
\hline \multicolumn{1}{|c|}{$\begin{array}{c}\text { TerraSAR- } \\
\mathrm{X} \text { data }-\mathrm{HH}\end{array}$} & \multicolumn{1}{|c|}{$\begin{array}{c}\text { Calibration phase } \\
\text { Model }\end{array}$} & $\mathrm{R}^{2}$ & \multicolumn{3}{|c|}{ Validation phase } \\
\hline $26^{\circ}-28^{\circ}$ & $m v(\%)=2.31 \sigma_{\mathrm{dB}}^{\circ}+37.19$ & 0.79 & 0.52 & 2.76 & 2.81 \\
$50^{\circ}-52^{\circ}$ & $m v(\%)=3.43 \sigma_{\mathrm{dB}}^{\circ}+54.30$ & 0.66 & 2.95 & 2.83 & 4.09 \\
\hline $26^{\circ}-28^{\circ}$ & $m v(\%)=1.67 \sigma_{\mathrm{dB}}^{\circ}\left(\theta_{\text {low }}\right)+0.55 \sigma_{\mathrm{dB}}^{\circ}\left(\theta_{\text {high }}\right)+38.22$ & 0.69 & 1.65 & 2.46 & 2.91 \\
and & & & & & \\
$50^{\circ}-52^{\circ}$ & & & & & \\
\hline
\end{tabular}

201 the sum of two functions that describe the dependence of the 202 radar signal on soil moisture $(f$ : linear) and surface roughness 203 ( $g$ : exponential) (e.g., [1] and [4])

$$
\sigma_{\mathrm{dB}}^{\circ}=f(m v, \theta)_{\mathrm{dB}}+g(r m s, \theta)_{\mathrm{dB}}=\delta, m v+\mu, e^{-k r m s}+\tau
$$

204 where $k$ is the radar wavenumber $\left(\sim 2 \mathrm{~cm}^{-1}\right.$ for TerraSAR-X). 205 This equation neglects the effect of the correlation length $206 L$ on the backscattering coefficient. To take account of the 207 correlation length, Zribi and Deschambre [1] proposed a new 208 roughness parameter $Z s$, defined by $\mathrm{rms}^{2} / L$, which is the 209 product of the rms surface height and the slope of the soil 210 surface $(r m s / L)$. Thus, the empirical model linking $\sigma^{\circ}$ and $Z s$ 211 could be written as $\sigma_{\mathrm{dB}}^{\circ}=\delta m v+\eta e^{-k Z s}+\psi$.

212 In the case of one SAR image characterized by one inci213 dence $\left(\theta=26^{\circ}-28^{\circ}\right.$ or $\left.50^{\circ}-52^{\circ}\right)$, inversion model is written as 214 follows:

$$
m v=\alpha \sigma^{\circ}(\theta)+\beta
$$

215 The use of two incidence angles eliminates the effects of 216 roughness and thus allows linking the backscattering coefficient 217 to the soil moisture only. For two images acquired with low 218 and high incidence angles, the estimate of soil moisture can 219 be obtained by solving (3) for two incidences (substituting the $220 e^{-k r m s}$ of $\sigma^{\circ}\left(\theta_{\text {low }}\right)$ into $\sigma^{\circ}\left(\theta_{\text {high }}\right)$

$$
m v=\alpha \sigma^{\circ}\left(\theta_{\text {low }}\right)+\beta \sigma^{\circ}\left(\theta_{\text {high }}\right)+\gamma .
$$

$221 \alpha$ and $\beta$ depend on $\delta$ and $\mu$, whereas $\gamma$ is a function of $\delta, \mu$, 222 and $\tau$ (in both incidence angles).

223 The form of (5) should be the same if the $Z s$ parameter was 224 used.

225 The empirical models given in (4) and (5) were then fitted to 226 experimental data acquired in 2008 and 2009 by using the least 227 squares method (cf. Table II). The validation of these models 228 was tested in using the data set of 2010 (13 points for each of 229 the two configurations $\mathrm{HH} 26^{\circ}$ and $\mathrm{HH} 50^{\circ}$ ). The inputs are the 230 mean backscattering coefficients in decibels calculated for each 231 reference field.

\section{RESUlTS AND DISCUSSION}

233 The inversion procedures were applied in order to retrieve 234 soil moisture. The results obtained in the validation phase 235 with one low incidence show inversion errors in the estimation

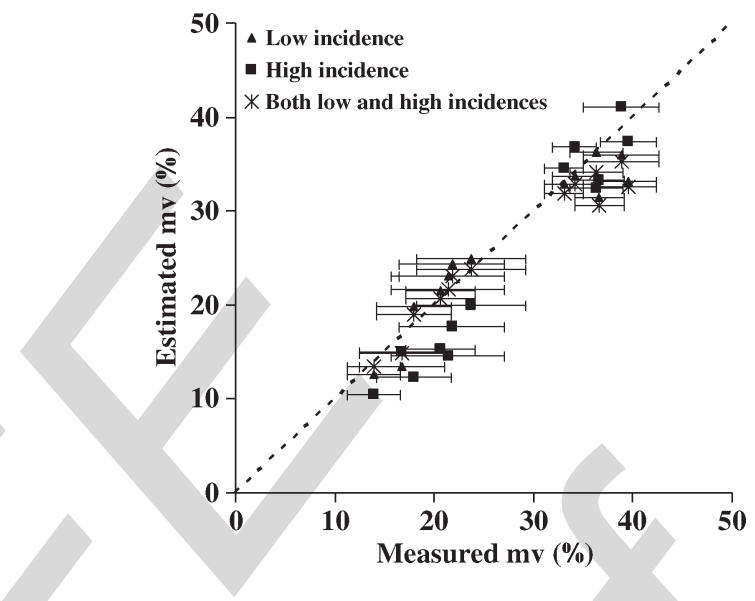

Fig. 4. Comparison between the estimated $m v$ values and those measured. The error bars on the measured soil moisture values correspond to one standard deviation.

of $m v$ of about 3\% for incidence angles. The use of high 236 incidences $\left(50^{\circ}-52^{\circ}\right)$ gives slightly poorer results with an rmse 237 of about $4 \%$. The accuracy of the soil moisture estimate remains 238 unchanged by using TerraSAR-X multi-incidence data (both 239 low and high incidence angles) with an rmse of about 3\% 240 (Table II). Fig. 4 shows the good agreement between estimated 241 and measured $m v$ values.

In contrast, large errors in the retrieved soil moisture were 243 observed at C-band for a single incidence angle (rmses of about 244 $6 \%$ for $20^{\circ}$ and $9 \%$ for $40^{\circ}$ ) [4]. This is due to the fact that the 245 radar signal is much more sensitive to surface roughness at high 246 radar wavelength. The accuracy is strongly improved with the 247 use of both low and high incidences (rmse of about 3.5\%) (e.g., 248 [1], [2], and [4]).

The dependence of the radar signal at X-band on surface 250 roughness in agricultural areas was described as weak by 251 several works ([8], [14], and [17]). Results of these studies 252 show that the influence of surface roughness on the radar signal 253 increases with increasing radar wavelength. Moreover, this 254 dependence is mainly significant for low levels of roughness. 255 At X-band, Baghdadi et al. [4], [8] showed that the sensitivity 256 of $\sigma^{\circ}$ to surface roughness becomes weak for $r m s>1 \mathrm{~cm} .257$ Thus, the effect of surface roughness on radar signal becomes 258 weak in X-band, which improves the estimates of soil moisture, 259 particularly for $r m s>1 \mathrm{~cm}$. Moreover, the multi-incidence 260 approaches become less effective because the effect of surface 261 roughness that we try to eliminate is relatively weak at X-band 262 compared to C-band. 
Author-produced version of the article published in IEEE Geoscience and remote sensing letters, 2012, 9(3), 512-516.

The original publication is available at http://ieeexplore.ieee.org

http://dx.doi.org/10.1109/LGRS.2011.2173155

BAGHDADI et al.: USE OF TerraSAR-X DATA TO RETRIEVE SOIL MOISTURE OVER BARE SOIL AGRICULTURAL FIELDS

TABLE III

TerraSAR-X Coverage Simulation For ORgeval Site Between SEPTEMBER 2 AND 12, 2010 (ORBIT CYCLE)

\begin{tabular}{|c|c|c|c|c|c|c|c|c|c|c|c|}
\hline \multirow{2}{*}{ Time } & $\begin{array}{c}02 \\
\text { sep. }\end{array}$ & $\begin{array}{c}03 \\
\text { sep. }\end{array}$ & $\begin{array}{c}04 \\
\text { sep. }\end{array}$ & $\begin{array}{c}05 \\
\text { sep. }\end{array}$ & $\begin{array}{c}06 \\
\text { sep. }\end{array}$ & $\begin{array}{c}07 \\
\text { sep. }\end{array}$ & $\begin{array}{c}08 \\
\text { sep. }\end{array}$ & $\begin{array}{c}09 \\
\text { sep. }\end{array}$ & $\begin{array}{c}10 \\
\text { sep. }\end{array}$ & $\begin{array}{c}11 \\
\text { sep. }\end{array}$ & $\begin{array}{c}12 \\
\text { sep. }\end{array}$ \\
\hline $\boldsymbol{\theta}\left(\mathbf{(}^{\circ}\right)$ & - & 39 & 58 & 50 & 26 & - & 26 & 50 & 58 & 39 & - \\
\hline
\end{tabular}

264

V. CONCLUSION

265 This study examined the potential of TerraSAR-X data for 266 estimating soil moisture $(m v)$ over bare soils. TerraSAR-X 267 images collected between 2008 and 2010 over two study sites in 268 France were used. SAR images were acquired at $\mathrm{HH}$ polariza269 tion and for incidence angles of $26^{\circ}, 28^{\circ}, 50^{\circ}$, and $52^{\circ}$. The goal 270 of this work was to compare estimates of $m v$ obtained from 271 various incidence configurations and to find the best sensor 272 configuration in incidence angle for measuring the bare soil 273 moisture.

274 This study tested empirical models for soil moisture inver275 sion from one incidence (low or high) and multi-incidence 276 TerraSAR-X data (both low and high incidences). The results 277 of this study may be summarized as follows. 286 plified algorithms for retrieving soil moisture from TerraSAR$287 \mathrm{X}$ data and for monitoring temporal moisture changes. Table III 288 lists the different observation possibilities for the Orgeval study 289 site within one orbit cycle (11 days). This site could be imaged 8 290 times within 11 days (two images for each following incidence: $291 \sim 26^{\circ}, 39^{\circ}, 50^{\circ}$, and $58^{\circ}$ ) and 24 times within one month. 292 The soil moisture mapping frequency with low incidence angle $293\left(26^{\circ}\right)$ or with both low and high incidence angles $\left(26^{\circ}\right.$ and $\left.50^{\circ}\right)$ 294 is possible six times within one month. The incidence of $39^{\circ} \mathrm{can}$ 295 also be used, which would increase to 12 the TerraSAR-X scene 296 number within one month. This very short revisit time makes 297 TerraSAR-X a very useful source for the soil moisture mapping. 298 Moreover, the increase in the acquisition frequency is much 299 awaited for the soil moisture data assimilation in hydrological 300 modeling.

301 In addition, the very high spatial resolution (metric) of the 302 TerraSAR-X sensor is also very promising for local estimation 303 of soil moisture at the within agricultural field scale. It offers a 304 great potential in terms of improving the quality of soil moisture 305 mapping for catchment areas where the parcels are of small 306 size.

\section{ACKNOWLEDGMENT}

308 The authors would like to thank the German Space Agency 309 (DLR) for kindly providing TerraSAR-X images within the framework of proposals HYD0007 and HYD0542, P. Ansart, 310 Y. Hachouch, and C. Loumagne for their logistic support during 311 the field campaigns, and TerraSAR-X Science Coordinators 312 A. Roth and U. Marschalk for their assistance.

\section{REFERENCES}

[1] M. Zribi and M. Dechambre, "A new empirical model to retrieve soil 315 moisture and roughness from C-band radar data," Remote Sens. Environ., 316 vol. 84, no. 1, pp. 42-52, Jan. 2003.

317

[2] H. S. Srivastava, P. Patel, M. L. Manchanda, and S. Adiga, "Use of 318 multi-incidence angle RADARSAT-1 SAR data to incorporate the effect 319 of surface roughness in soil moisture estimation," IEEE Trans. Geosci. 320 Remote Sens., vol. 41, no. 7, pp. 1638-1640, Jul. 2003.

321

[3] Y. Oh, "Quantitative retrieval of soil moisture content and surface rough- 322 ness from multipolarized radar observations of bare soil surfaces," IEEE 323 Trans. Geosci. Remote Sens., vol. 42, no. 3, pp. 596-601, Mar. $2004 . \quad 324$

[4] N. Baghdadi, N. Holah, and M. Zribi, "Soil moisture estimation using 325 multi-incidence and multi-polarization ASAR SAR data," Int. J. Remote 326 Sens., vol. 27, no. 10, pp. 1907-1920, 2006.

[5] A. K. Fung, Microwave Scattering and Emission Models and Their Appli- 328 cations. Boston, MA: Artech House, 1994, 573 pages.

[6] H. Holah, N. Baghdadi, M. Zribi, A. Bruand, and C. King, "Potential of 330 ASAR/ENVISAT for the characterisation of soil surface parameters over 331 bare agricultural fields," Remote Sens. Environ., vol. 96, no. 1, pp. 78-86, 332 May 2005.

333

7] F. T. Ulaby, P. P. Batlivala, and M. C. Dobson, "Microwave backscat- 334 ter dependence on surface roughness, soil moisture, and soil texture: 335 Part I-Bare soil," IEEE Trans. Geosci. Electron., vol. GE-16, no. 4, 336 pp. 286-295, Oct. 1978.

337

[8] N. Baghdadi, M. Zribi, C. Loumagne, P. Ansart, and T. Paris Anguela, 338 "Analysis of TerraSAR-X data and their sensitivity to soil surface parame- 339 ters over bare agricultural fields," Remote Sens. Environ., vol. 112, no. 12, 340 pp. 4370-4379, Dec. 2008.

341

[9] M. Aubert, N. Baghdadi, M. Zribi, A. Douaoui, C. Loumagne, F. Baup, 342 M. El Hajj, and S. Garrigues, "Analysis of TerraSAR-X data sensitivity to 343 bare soil moisture, roughness, composition and soil crust," Remote Sens. 344 Environ., vol. 115, no. 8, pp. 1801-1810, Aug. 2011.

[10] T. Fritz, TerraSAR-X Ground Segment Level 1b Product Format 346 Specification (10.12.2007), p. 257, 2007, Issue, 1.3, Doc.: TX-GS-DD- 347 3307. [Online]. Available: http://www.dlr.de/tsx/documentation/TX-GS- 348 DD-3307_Level-1b-Product-Format-Specification_1.3.pdf 349

[11] N. Baghdadi, O. Cerdan, M. Zribi, V. Auzet, F. Darboux, M. El Hajj, 350 and R. Bou Kheir, "Operational performance of current synthetic aper- 351 ture radar sensors in mapping soil surface characteristics: Application to 352 hydrological and erosion modeling," Hydrol. Process., vol. 22, no. 1, 353 pp. 9-20, Jan. 2008.

354

12] S. Le Hégarat-Mascle, M. Zribi, F. Alem, A. Weisse, and C. Loumagne, 355 "Soil moisture estimation from ERS/SAR data: Toward an operational 356 methodology," IEEE Trans. Geosci. Remote Sens., vol. GRS-24, no. 12, 357 pp. 2647-2658, Dec. 2002.

358

[13] A. Quesney, S. Le Hégarat-Mascle, O. Taconet, D. Vidal-Madjar, 359 J. P. Wingneron, C. Loumagne, and M. Normand, "Estimation of water- 360 shed soil moisture index from ERS/SAR data," Remote Sens. Environ., 361 vol. 72, no. 3, pp. 290-303, Jun. 2000.

362

[14] F. T. Ulaby, R. K. Moore, and A. K. Fung, Microwave Remote Sensing, 363 Active and Passive, From Theory to Applications, vol. 3. Norwood, MA: 364 Artech House, 1986, 1098 pages.

365

[15] Y. Oh, K. Sarabandi, and F. T. Ulaby, "An empirical model and an inver- 366 sion technique for radar scattering from bare soil surfaces," IEEE Trans. 367 Geosci. Remote Sens., vol. 30, no. 2, pp. 370-381, Mar. 1992.

368

[16] N. Baghdadi, C. King, A. Bourguignon, and A. Remond, "Potential of 369 ERS and RADARSAT data for surface roughness monitoring over bare 370 agricultural fields: Application to catchments in Northern France," Int. J. 371 Remote Sens., vol. 23, no. 17, pp. 3427-3442, 2002.

372

[17] N. Baghdadi, N. Holah, P. Dubois, L. Prévot, S. Hosford, A. Chanzy, 373 X. Dupuis, and M. Zribi, "Discrimination potential of X-band polari- 374 metric SAR data," Int. J. Remote Sens., vol. 25, no. 22, pp. 4933-4942, 375 2004. 


\section{AUTHOR QUERIES}

\section{AUTHOR PLEASE ANSWER ALL QUERIES}

AQ1 = "In" was changed to "by." Please check if the original thought was retained.

AQ2 = Please provide the expanded form of the acronym "COSMO-SkyMed."

AQ3 = Please provide the expanded form of the acronym "ORFEO."

AQ4 = "French Space Study Center" was changed to "National Space Study Center." Please check if appropriate.

AQ5 = Please provide the expanded form of the acronym "UMR TETIS."

AQ6 = The acronyms "CESBIO" and "IRD" were defined as "Centre d'Etudes Spatiales de la BIOsphère" and "Institut de Recherche pour le Développement," respectively. Please check if appropriate.

AQ7 = Please provide the expanded form of the acronym "PALSAR."

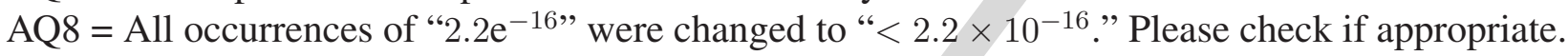
AQ9 = Please provide the expanded forms of the acronyms "ERS," "RADARSAT," and "ASAR."

AQ10 = This sentence was reworded for clarity. Please check if the original thought was retained.

AQ11 = Please check the URL provided in Ref. [10]. Page was not found.

END OF ALL QUERIES 